\title{
Induction of Terminal Differentiation in Human K562 Erythroleukemia Cells by Arabinofuranosylcytosine
}

Cynthia Luisi-Deluca, Thomas Mitchell, David Spriggs, and Donald W. Kufe

Division of Medicine, Dana-Farber Cancer Institute, Harvard Medical School, Boston, Massachusetts 02115

A that continur promyelocytes to $1-\beta$-D-arabinofuranosylcytosine (araC) results in the induction of terminal differentiation to monocyte-like cells. The present study extends these findings by demonstrating that ara-C induces hemoglobin synthesis in human K562 erythroleukemia cells. This effect occurs maximally at an ara-C concentration ( 5 $\times 10^{-7} \mathrm{M}$ ) that results in $\mathrm{K} 562$ cytostasis. In contrast to the reversible effects of hemin and hydroxyurea on globin synthesis in this cell line, we have found that the induction of $\mathrm{K} 562$ hemoglobin synthesis by ara-C is irreversible. An induction of K562 hemoglobin synthesis also occurs with aphidicolin, another inhibitor of Sphase DNA synthesis, but not with vinblastine, an inhibitor of mitosis. Finally, ara-C induction of a differentiated K562 phenotype is accompanied by the loss of self-renewal capacity, a finding consistent with terminal differentiation.

\section{Introduction}

$1-\beta$-D-arabinofuranosylcytosine $(\operatorname{ara}-\mathrm{C})^{1}$ is one of the most effective agents in the treatment of human acute myelogenous leukemia (1). The basis for this selectivity against leukemic cells has remained unclear. Ara-C incorporates specifically into DNA, but not into RNA, of human myeloblasts (2). The incorporated ara- $\mathrm{C}$ residue behaves as a relative chain terminator, and the extent of ara-C incorporation into DNA correlates significantly with inhibition of DNA synthesis (3). The

\footnotetext{
Address reprint requests to Dr. Kufe.

Received for publication 2 April 1984 and in revised form 9 May 1984.
}

1. Abbreviation used in this paper: ara-C, 1- $\beta$-D-arabinofuranosylcytosine.

J. Clin. Invest.

(c) The American Society for Clinical Investigation, Inc.

0021-9738/84/09/0821/07 \$1.00

Volume 74, September 1984, 821-827 inhibition of replicative DNA synthesis by ara-C causes DNA fragmentation (4). Furthermore, there is a highly significant relationship between the incorporation of ara-C into DNA and the loss of leukemic cell clonogenic survival $(2,5,6)$. These findings have suggested that the incorporation of ara-C into leukemic cell DNA is responsible for cytotoxicity.

An inhibition of DNA synthesis by sublethal doses of ara$\mathrm{C}$ is associated with the induction of differentiation in HL-60 human promyelocytic leukemic cells (7). Similar phenotypic changes have been observed with aphidicolin, an inhibitor of DNA polymerase- $\alpha$, which is not incorporated into DNA (8). The induction of differentiation by both of these agents has been accompanied by the loss of clonogenic survival, suggesting that terminal differentiation of HL-60 cells can be induced by drugs known to inhibit DNA synthesis. It is not clear, however, whether this effect contributes to decreases in the self-renewal capacity of acute myeloblastic leukemia cells after ara-C treatment (9).

The K562 human leukemic cell line was established from a patient with chronic myelogenous leukemia (10). K562 cells can be induced by hemin to form embryonic and fetal hemoglobins (11-13). The induction of K562 cells by hemin has been shown to be mediated at a transcriptional level (14), with increases in both the rate of transcription and the level of accumulation of $\zeta-, \epsilon-, \gamma$ - and $\alpha$-globin messenger RNAs (15). In contrast, treatment with hydroxyurea has resulted in an increase in the rate of transcription of primarily the $\zeta$ - and $\epsilon$-globin genes (15). Furthermore, the effects of hemin and hydroxyurea on the induction of K562 globin synthesis have been found to be reversible and therefore not associated with the induction of terminal differentiation $(12,16)$.

This report extends our previous findings in HL-60 cells by monitoring the effects of ara-C on the induction of differentiation in K562 cells. The results demonstrate that ara-C is a potent inducer of $\mathrm{K} 562$ hemoglobin expression and that, in contrast to the effects hemin and hydroxyurea, this effect is irreversible. Furthermore, the appearance of a differentiated K562 phenotype is associated with the loss of clonogenic survival, suggesting that ara-C treatment results in terminal differentiation. These findings are compared with those obtained with other inhibitors of cellular proliferation. 


\section{Methods}

Cell culture. K562 cells (obtained from Drs. Lozzio, Knoxville, TE and the Institute for Medical Research, Camden, NJ) were maintained at a density of $1-2 \times 10^{5}$ cells/ml in RPMI 1640 medium (Flow Laboratories Inc., McLean, VA) containing $2 \mathrm{mM}$ L-glutamine and $1 \%$ penicillin/streptomycin (both from Gibco Laboratories, Gibco Div., Grand Island, NY), and $10 \%$ heat-inactivated fetal bovine serum (Flow Laboratories Inc.), in a $5 \% \mathrm{CO}_{2}$ humidified atmosphere at $37^{\circ} \mathrm{C}$. The $\mathrm{K} 562$ cells were grown in suspension culture in the presence of varying concentrations of ara-C (Sigma Chemical Co., St. Louis, MO), aphidicolin (NSC-234714; provided by Dr. J. Douros, National Cancer Institute, Bethesda, MD), hydroxyurea, or vinblastine (both from Sigma Chemical Co.). Cultures were scored for benzidine-positive cells by the wet benzidine method (17). Viability was monitored by trypan blue exclusion.

Clonogenic survival of K562 cells. K562 cells in logarithmic growth phase were harvested and resuspended in complete medium $\left(1 \times 10^{5}\right.$ cells $/ \mathrm{ml})$. Ara-C $\left(5 \times 10^{-7} \mathrm{M}\right)$ was added and the cells were incubated for $12-120 \mathrm{~h}$. After drug exposure, cells were pelleted, washed in phosphate-buffered saline, and resuspended in drug-free medium. Cells $\left(3 \times 10^{3}\right)$ were plated in 0.4\% Bacto-Agar (Difco Laboratories Inc., Detroit, MI) containing RPMI 1640 medium, 10\% fetal bovine serum, $2 \mathrm{mM}$ L-glutamine, and $1 \%$ penicillin/streptomycin. Colonies that contained 50 cells or more were scored after $7 \mathrm{~d}$. Clonogenicity was determined as the percentage colonies formed by drug-treated cells compared with those formed by untreated cells. Cloning efficiency of untreated K362 cells was $15 \%$.

Gel electrophoresis. Electrophoresis of cell lysates was carried out in sodium dodecyl sulfate (SDS)-15\% polyacrylamide gels $(18,19)$. Cell lysates were prepared by washing the cell pellets twice in cold phosphate-buffered saline and resuspending them in SDS sample solution (19). Proteins were detected by staining with Coomassie Brilliant Blue R.

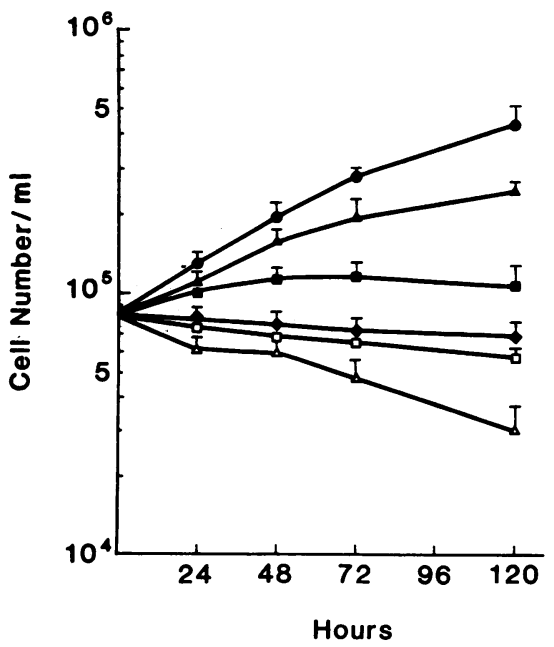

Figure 1. Inhibition of K562 cell growth by ara-C. K562 cells ( 2 $\times 10^{5} \mathrm{ml}$ ) either received no treatment $(\bullet)$ or were exposed to ara-C at concentrations of $10^{-8}(\Delta), 10^{-7}(\Delta), 5 \times 10^{-7}(\bullet), 10^{-6}(\square)$, or $10^{-5}$ $M(\Delta)$. Viability as determined by trypan blue exclusion was $>95 \%$ at $120 \mathrm{~h}$ of exposure to $5 \times 10^{-7} \mathrm{M}$ ara-C

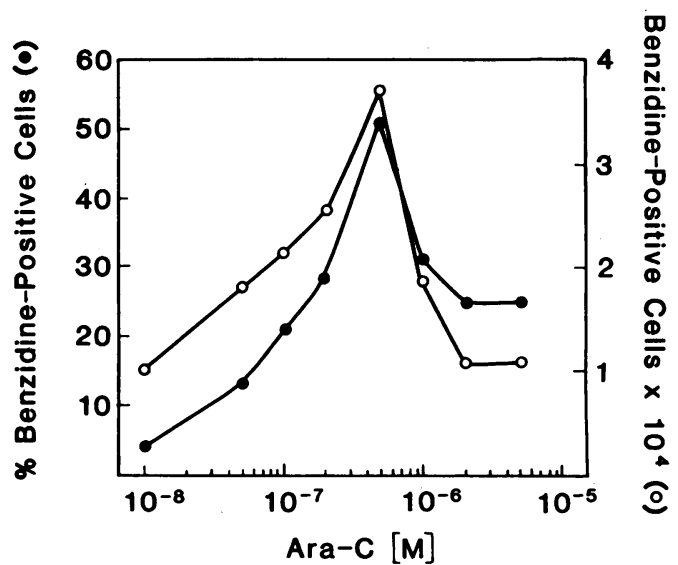

Figure 2. Effect of ara-C on percentage and absolute number of benzidine-positive cells. $\mathrm{K} 562$ cells $\left(2 \times 10^{5} / \mathrm{ml}\right)$ were exposed to varying concentrations of ara-C for $120 \mathrm{~h}$. The percentage of benzidine-positive cells was determined by the wet benzidine method (17). The absolute number of benzidine-positive cells was determined by multiplication of the number of viable cells by the percentage of benzidine-positive cells.

\section{Results}

K562 cells were exposed to concentrations of ara- $\mathrm{C}$ ranging from $10^{-8}$ to $10^{-5} \mathrm{M}$ for 24-120 h. Fig. 1 illustrates the effect of drug exposure on cell proliferation. Ara-C concentrations of $10^{-8}$ and $10^{-7} \mathrm{M}$ partially slowed cell growth, whereas concentrations of $10^{-6}$ and $10^{-5} \mathrm{M}$ resulted in the loss of cell viability. Static cell concentrations without evidence of lethality

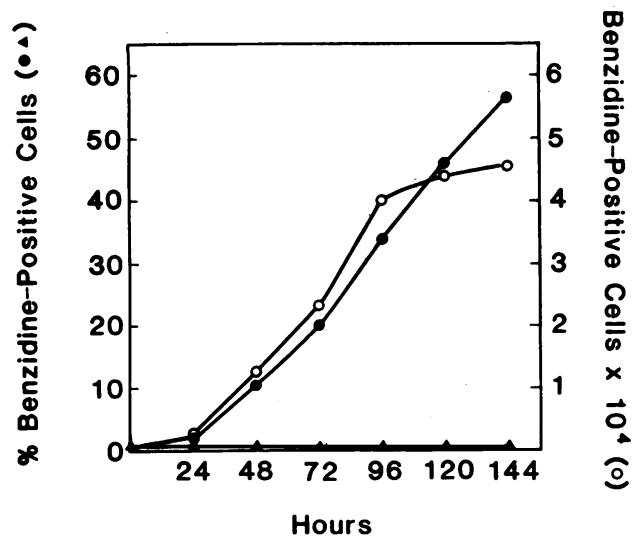

Figure 3. Effect of duration of ara-C treatment on benzidine-positive cells. K562 cells $\left(2 \times 10^{5} / \mathrm{ml}\right)$ were exposed to $5 \times 10^{-7} \mathrm{M}$ ara-C for 24 to $144 \mathrm{~h}$. The percentage benzidine-positive cells was determined by the wet benzidine method at the indicated times. The absolute number of benzidine-positive cells was calculated by multiplication of the number of viable cells by the percentage of benzidine-positive cells. 


\section{A}

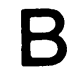

\section{C}
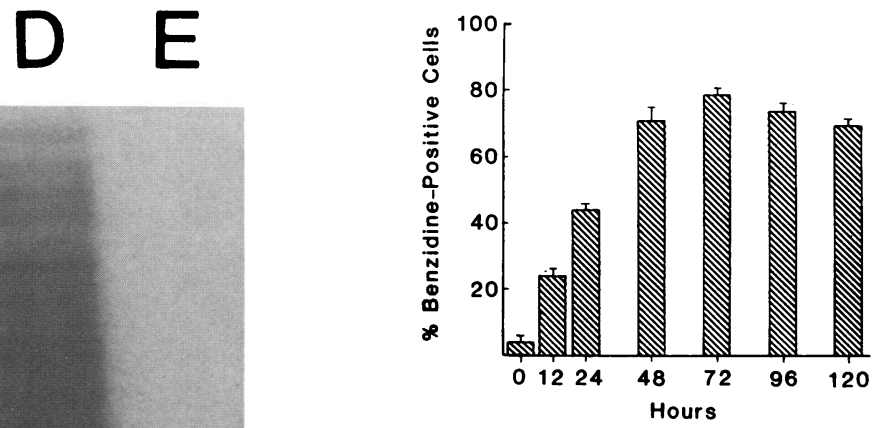

Figure 5. Commitment after exposure to varying durations of ara-C treatment. K562 cells were exposed to $5 \times 10^{-7} \mathrm{M}$ ara-C for from 0 to $120 \mathrm{~h}$. At the times indicated, the cells were harvested, washed, and resuspended in drug-free medium. The percentage benzidine-positive cells was monitored for each group after a total incubation of $120 \mathrm{~h}$ in ara- $\mathrm{C}$ and drug-free medium. The results represent the mean $\pm \mathrm{SD}$ of four determinations.

by trypan blue exclusion were achieved by exposure to 5 $\times 10^{-7} \mathrm{M}$ ara-C.

The effects of ara-C on the appearance of a differentiated K562 phenotype was next examined at drug concentrations of $10^{-8}$ to $5 \times 10^{-6} \mathrm{M}$. Benzidine-positive cells were scored at $120 \mathrm{~h}$. The results obtained are illustrated in Fig. 2. There was a progressive increase in the percentage of benzidine-positive cells at concentrations of $10^{-8}$ to $5 \times 10^{-7} \mathrm{M}$ ara-C, with $>50 \%$ of the cells expressing a differentiated phenotype. In contrast, higher concentrations of ara-C resulted in progressive declines in the percentage of benzidine-positive cells. The absolute number of differentiated cells was calculated by the multiplication of the number of viable cells by the percentage of benzidine-positive cells. The results demonstrate an absolute increase in benzidine-positive cells which was maximal at 5 $\times 10^{-7} \mathrm{M}$ ara-C and declined with higher drug exposures (Fig. 2). An absolute increase in benzidine-positive cells excludes the possibility of a selective loss of more rapidly proliferating and undifferentiated cells during drug exposure.

The effects of duration of drug exposure on the induction of benzidine-positive K562 cells were monitored from 24 to $144 \mathrm{~h}$. The increase in percentage of benzidine-positive cells was linear during exposure to $5 \times 10^{-7} \mathrm{M}$ ara-C (Fig. 3). Similarly, the increase in the absolute number of benzidinepositive cells was also linear, with the exception of the 144-h drug exposure, which resulted in a loss of cell viability. Thus, the accumulation of benzidine-positive $\mathrm{K} 562$ cells by ara-C is maximal at a concentration resulting in cytostatic cell growth, and the percentage benzidine-positive cells is linear through $144 \mathrm{~h}$ of drug exposure.

The induction of K562 hemoglobin synthesis by ara-C was further evaluated by polyacrylamide gel electrophoresis (Fig.

Figure 4. Gel electrophoresis of K562 cells. K562 cells $\left(5 \times 10^{4} / \mathrm{ml}\right)$ received either no treatment (lane $B$ ), treatment with $20 \mu \mathrm{M}$ hemin for $6 \mathrm{~d}$ (lane $C$ ), or treatment with $5 \times 10^{-7} \mathrm{M}$ ara-C for $6 \mathrm{~d}$ (lane $D$ ). Lanes $A$ and $E$ represent globin preparations from human umbilical cord blood (28). 


\section{$\begin{array}{lllllll}A & B & C & D & E & F & G\end{array}$}

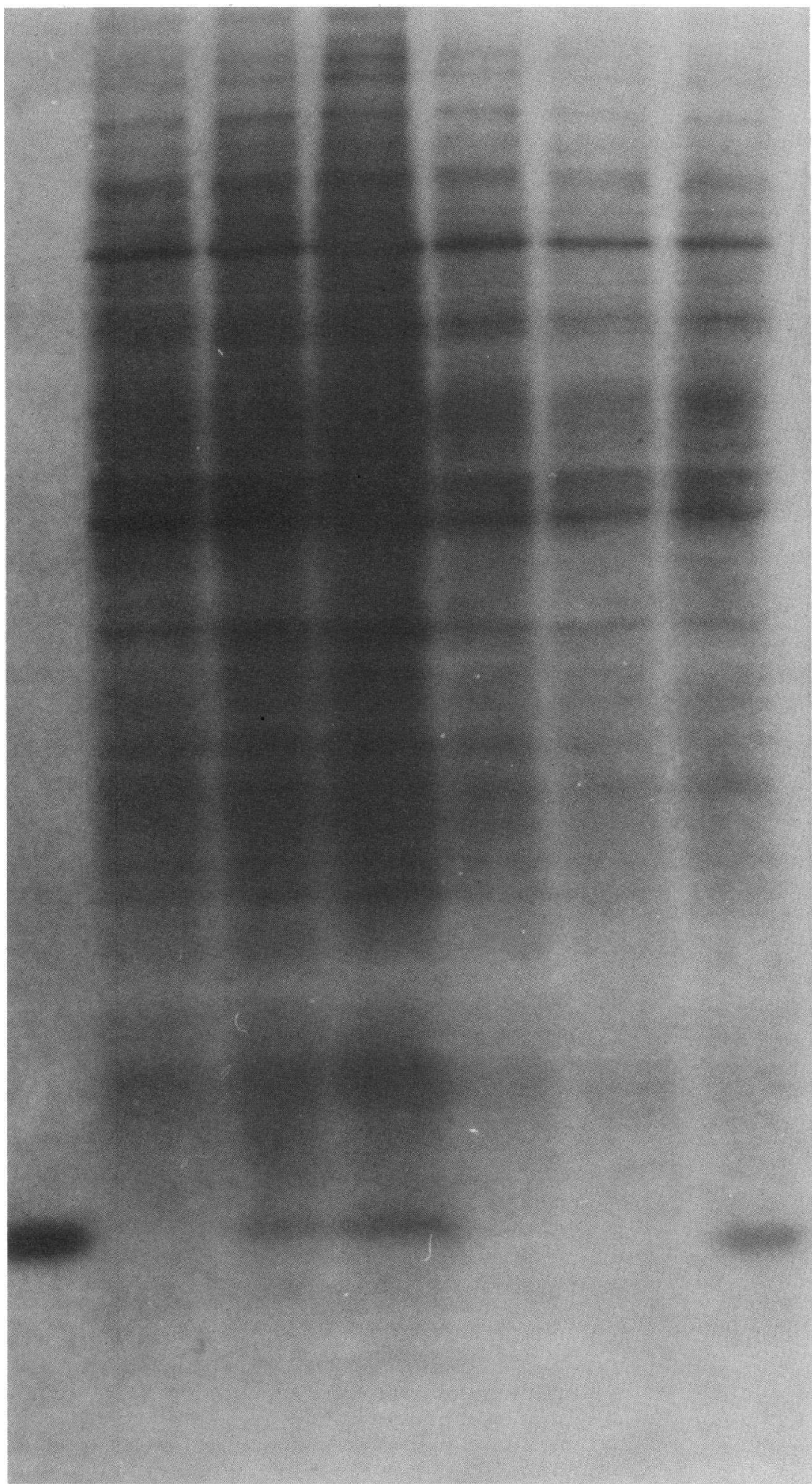

Figure 6. Irreversibility of fetal globin synthesis after exposure to ara-C. $\mathrm{K} 562$ cells $\left(5 \times 10^{4} / \mathrm{ml}\right)$ received either no treatment (lane $B$ ), treatment with $20 \mu \mathrm{M}$ hemin for $72 \mathrm{~h}$ (lane $C$ ), or treatment with $5 \times 10^{-7} \mathrm{M}$ ara-C for $72 \mathrm{~h}$ (lane $D$ )

The cells were then washed twice and resuspended in drug-free medium for an additional $3 \mathrm{~d}$. The untreated cells (lane $E$ ), hemin treated cells (lane $F$ ), and the ara-C treated cells (lane $G$ ) were then analyzed for the presence of globin. Lane $A$ represents a globin preparation from human umbilical cord blood. 
4). The K562 cells were incubated in $5 \times 10^{-7} \mathrm{M}$ ara-C for $144 \mathrm{~h}$. The results obtained demonstrate the synthesis of a protein that is undetectable in uninduced K562 cells and that comigrates with globin from human umbilical cord blood. A similar induction of globin synthesis occurred in K562 cells treated with $20 \mu \mathrm{M}$ hemin for $6 \mathrm{~d}$ (Fig. 4). These results agree with the increase in benzidine-positive cells after ara-C treatment and support the finding that ara-C, like hemin, induces the synthesis of hemoglobin.

Since the induction of K562 hemoglobin synthesis by hemin and hydroxyurea is reversible, it was of interest to determine whether the removal of ara-C after induction would also result in a loss of detectable globin. K562 cells were exposed to $5 \times 10^{-7} \mathrm{M}$ ara-C for from 12 to $120 \mathrm{~h}$. The cells were then washed, resuspended in complete drug-free medium, and assayed for benzidine-positive cells at $120 \mathrm{~h}$. The results demonstrate that exposures of 12 and $24 \mathrm{~h}$ were sufficient to result in a significant increase in benzidine-positive cells after reculturing in the absence of drug (Fig. 5). Furthermore, $48 \mathrm{~h}$ of ara- $C$ exposure resulted in $>70 \%$ benzidine-positive cells, a finding comparable to that obtained with exposures of 72,96 , and $120 \mathrm{~h}$. These results indicate that shorter exposures of up to $48 \mathrm{~h}$ are sufficient to induce maximally hemoglobin synthesis.

The irreversible induction of hemoglobin synthesis in K562 cells by ara-C was confirmed by polyacrylamide gel electrophoresis (Fig. 6). Globin synthesis was detectable in cells treated with ara-C or hemin for $72 \mathrm{~h}$. These cells were then washed free of inducer and maintained in drug-free medium for an additional $3 \mathrm{~d}$. Under these experimental conditions, globin synthesis was detectable in ara-C treated cells but not in the hemin-treated cells. This finding confirms the reversible induction of globin synthesis by hemin and demonstrates the irreversible induction by ara-C.

The irreversible induction of hemoglobin synthesis by ara$C$ suggested that this effect could be associated with terminal differentiation. The $\mathrm{K} 562$ cells were treated with $5 \times 10^{-7} \mathrm{M}$ ara-C for from 12 to $120 \mathrm{~h}$. Cells were then washed free of drug and monitored for clonogenic survival. The results obtained are illustrated in Fig. 7. A 24-h exposure to ara-C resulted in $>70 \%$ loss of clonogenic survival, whereas a 48 -h exposure reduced self-renewal capacity by $>95 \%$. These observations indicate that the induction of hemoglobin synthesis by ara- $\mathrm{C}$ is associated with a terminal process.

It was also interesting to compare these effects of ara-C with those of other inhibitors of DNA synthesis. A 5-d exposure to varying concentrations of hydroxyurea $\left(10^{-5}\right.$ to 5 $\times 10^{-3} \mathrm{M}$ ) resulted in $\sim 20 \%$ benzidine-positive cells (Fig. 8). In contrast, a 5-d exposure to aphidicolin $\left(5 \times 10^{-7}\right.$ to $10^{-3}$ $M)$ resulted in almost $50 \%$ benzidine positive-cells at a concentration of $5 \times 10^{-5} \mathrm{M}$. Maximum induction of benzidinepositive cells occurred at concentrations of hydroxyurea and aphidicolin that resulted in cytostasis. The results obtained with aphidicolin were similar to those obtained with ara-C, whereas both ara-C and aphidicolin were more effective in

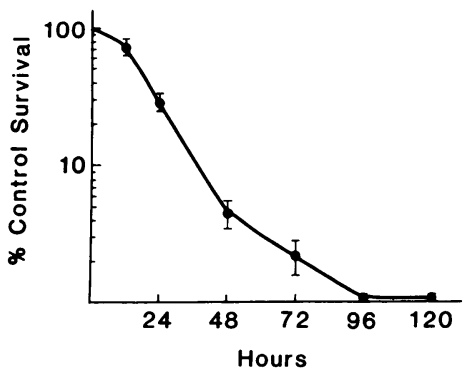

Figure 7. Effect of ara-C on K562 clonogenic survival. $\mathrm{K} 562$ cells were treated with $5 \times 10^{-7} \mathrm{M}$ ara-C for 12 to $120 \mathrm{~h}$. At the indicated times, the cells were harvested, washed, and plated in agar. The number of colonies containing 50 or more cells was determined after $7 \mathrm{~d}$. Results are expressed as the mean $\pm \mathrm{SD}$ of four determinations.

inducing hemoglobin synthesis than was hydroxyurea. In contrast, hemoglobin synthesis was not detectable by benzidine staining (data not shown) after similar 5-d exposures to varying concentrations of vinblastine (range: $10^{-10}$ to $5 \times 10^{-4} \mathrm{M}$; cytostatic: $1 \times 10^{-8} \mathrm{M}$ ).

\section{Discussion}

Although a variety of chemotherapeutic agents can induce human myeloid leukemia cell differentiation $(20,21)$, their biochemical mechanisms of action vary considerably. We have employed defined inhibitors of DNA synthesis to determine whether the inhibition of DNA replication at the level of the DNA polymerase-template complex can result in HL-60 differentiation. Previous studies with ara-C and aphidicolin demonstrated the induction of HL-60 differentiation along a monocytic lineage (7). The findings were consistent with a terminal process since the appearance of a mature phenotype was associated with a loss of self-renewal capacity. The use of higher drug concentrations resulted in immediate cell lethality

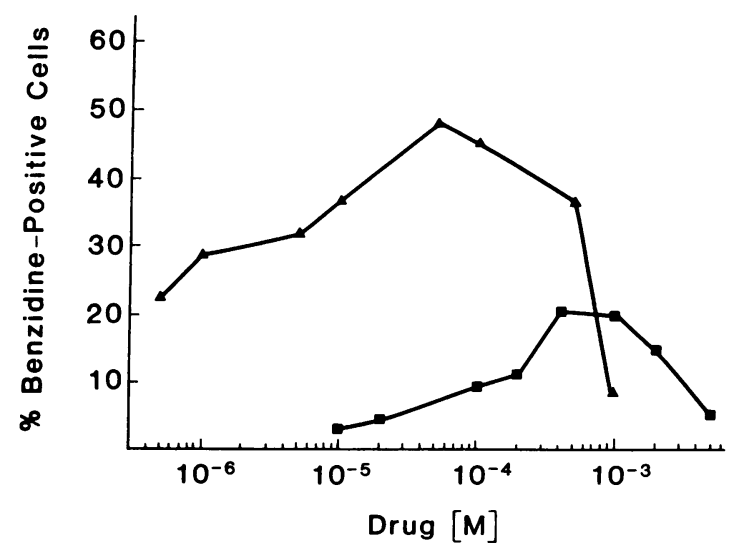

Figure 8. Effect of aphidicolin and hydroxyurea on percentage benzidine-positive K562 cells. K562 cells were exposed to varying concentrations of aphidicolin ( $\Delta$ ) or hydroxyurea $(\boldsymbol{\square})$ for $120 \mathrm{~h}$. Cells were then monitored by the wet benzidine method. 
and precluded the appearance of monocyte differentiation markers.

The present studies have monitored the effects of ara-C on the induction of hemoglobin in the K562 erythroleukemia cell line. The results are similar in certain respects to those obtained in our previous studies. Ara-C treatment of K562 cells resulted in the appearance of a differentiated phenotype, as determined by accumulation of hemoglobin. This effect was maximal at an ara-C concentration $\left(5 \times 10^{-7} \mathrm{M}\right)$ that resulted in K562 cytostasis. Higher concentrations of drug resulted in cell lethality and a decrease in the percentage of benzidinepositive cells. Of particular interest is the demonstration that this effect was irreversible, a finding that contrasts with the reversible effects of hemin and hydroxyurea on hemoglobin synthesis in this cell line $(12,16)$. More important, the induction of a differentiated K562 phenotype by ara-C was accompanied by the loss of self-renewal capacity, an observation consistent with a process of terminal differentiation.

Previous studies have shown that the inhibition of eukaryotic DNA replication results in an aberrant form of DNA synthesis, with certain segments of DNA being replicated more than once in a single cell cycle (22-24). This form of aberrant DNA synthesis occurs after the inhibition of DNA replication by ara-C $(22,23)$. The additional copies of certain segments of DNA might result in the accumulation of DNA fragments and an alteration of gene expression. We have previously shown that both ara-C and aphidicolin cause an accumulation of DNA strand breaks in replicating DNA (4). Although it is not clear what mechanism is responsible for altered gene expression during the treatment of HL-60 and K562 cells with ara-C, other inhibitors of S-phase DNA replication, such as aphidicolin and hydroxyurea, can induce similar phenotypic changes. The induction of K562 hemoglobin synthesis, however, has not been detectable after the treatment of these cells with nonlethal concentrations of vinblastine, an inhibitor of mitosis. Studies are in progress to determine more precisely the types of globin chains induced by ara-C and whether these genes are amplified by inhibition of replicative DNA synthesis.

Finally, the induction of leukemia cell differentiation by ara-C and other chemotherapeutic agents known to inhibit DNA synthesis has not as yet been shown to occur in the clinical setting. Thus, the present findings may be limited to human leukemic cell lines established for long-term growth in tissue culture. Although low doses of ara-C have recently been used successfully in the treatment of preleukemia and acute leukemia (25-27), this effect probably occurs as a result of clonal selection rather than of induction of terminal differentiation. Further clinical studies are required to address this issue.

\section{Acknowledgments}

This investigation was supported by U. S. Public Health Service grants CA-29431 and CA-34183 awarded by the National Cancer Institute of the Department of Health and Human Services, and by a Faculty Research Award from the American Cancer Society to Dr. Kufe.

\section{References}

1. Frei, E., J. Bickers, J. Hewlett, M. Lane, W. Leary, and R. Talley. 1969. Dose schedule and antitumor studies of arabinosyl cytosine. Cancer Res. 29:1325-1332.

2. Major, P., E. M. Egan, G. Beardsley, M. Minden, and D. Kufe. 1981. Lethality of human myeloblasts correlates with the incorporation of ara-C into DNA. Proc. Natl. Acad. Sci. USA. 78:3235-3239.

3. Major, P., E. M. Egan, D. Herrick, and D. Kufe. 1982. The effect of ara-C incorporation on DNA synthesis. Biochem. Pharmacol. 31:2937-2940.

4. Fram, R., and D. Kufe. 1982. DNA strand breaks caused by inhibitors of DNA synthesis: $1-\beta$-D-arabinofuranosylcytosine and aphidicolin. Cancer Res. 42:4050-4053.

5. Kufe, D., P. Major, E. M. Egan, and P. Beardsley. 1980. Incorporation of ara-C into L1210 DNA as a correlate of cytotoxicity. J. Biol. Chem. 255:8997-9000.

6. Kufe, D., D. Spriggs, E. M. Egan, and D. Munroe. 1984. Relationships between ara-CTP pools, formation of (ara-C) DNA and cytotoxicity of human leukemia cells. Blood. 64:54-58.

7. Griffin, J., D. Munroe, P. Major, and D. Kufe. 1982. Induction of differentiation of human myeloid leukemia cell by inhibitors of DNA synthesis. Exp. Hematol. 10:744-781.

8. Huberman, J. 1981. New views on the biochemistry of eukaryotic DNA replication by aphidicolin, an unusual inhibitor of DNA polymerase alpha. Cell. 23:647-648.

9. McCulloch, E., R. Buick, J. Curtis, H. Messner, and J. Senn. 1981. The heritable nature of clonal characteristics in acute myeloblastic leukemia. Blood. 58:105-109.

10. Lozzio, B., and C. Lozzio. 1979. Properties and usefulness of the original K562 human myelogenous leukemia cell line. Leukemia Res. 3:363-370.

11. Rutherford, T., J. Clegg, and D. Weatherall. 1979. K562 human leukemic cells synthesize embryonic hemoglobin in response to hemin. Nature (Lond.). 280:164-165.

12. Dean, A., F. Erard, A. Schneider, and A. Schechter. 1981. Induction of hemoglobin accumulation in human K562 cells by hemin is reversible. Science (Wash. DC). 212:459-461.

13. Rutherford, T., J. Clegg, D. Higgs, R. Jones, J. Thompson, and D. Weatherall. 1981. Embryonic erythroid differentiation in the human leukemic cell line K562. Proc. Natl. Acad. Sci. USA. 78:348352.

14. Dean, A., T. Ley, R. Humphries, M. Fordis, and A. Schechter. 1983. Inducible transcription of five globin genes in K562 human leukemic cells. Proc. Natl. Acad. Sci. USA. 80:5515-5519.

15. Charnay, P., and T. Maniatis. 1983. Transcriptional regulation of globin gene expression in the human erythroid cell line K562. Science (Wash. DC). 220:1281-1283.

16. Erard, F., A. Dean, and A. Schechter. 1981. Inhibitors of cell division reversibly modify hemoglobin concentration in human erythroleukemia K562 cells. Blood. 58:1236-1239.

17. Orkin, S., D. Swan, and P. Leder. 1975. Differentiation in erythroleukemia cells and their somatic hybrids. Proc. Natl. Acad. Sci. USA. 72:98-102.

18. Laemmli, U. 1970. Cleavage of structural proteins during the assembly of the head of bacteriophage T4. Nature (Lond.). 227:680685. 
19. Manservigi, R., P. Spear, and A. Buchan. 1977. Cell fusion induced by herpes simplex virus is promoted and suppressed by different viral glycoproteins. Proc. Natl. Acad. Sci. USA. 74:39133917.

20. Bodner, A., R. Ting, and R. Gallo. 1981. Induction of differentiation of human promyelocytic leukemia cells (HL-60) by nucleosides and methotrexate. J. Natl. Cancer Inst. 67:1025-1030.

21. Lotem, J., and L. Sachs. 1980. Potential pre-screening for therapeutic agents that induce differentiation in human myeloid leukemia cells. Int. J. Cancer. 25:561-564.

22. Woodcock, D., and I. Cooper. 1981. Evidence for double replication of chromosomal DNA segments as a general consequence of DNA replication inhibition. Cancer Res. 41:2483-2490.

23. Woodcock, D., K. Adams, and I. Cooper. 1982. Relationship between aberrant DNA replication and loss of cell viability in Chinese Hamster Ovary CHO-K1 Cells. Cancer Res. 42:4744-4752.
24. Brown, P., T. Tlsty, and R. Schimke. 1983. Enhancement of methotrexate resistance and dihydrofolate reductase gene amplification by treatment of mouse 3T6 cells with hydroxyurea. Mol. Cell. Biol. 6:1097-1107.

25. Wisch, J., J. Griffin, and D. Kufe. 1983. Response of preleukemic syndromes to continuous infusion of low-dose cytarabine. $N$. Engl. $J$. Med. 309:1599-1602.

26. Castaigne, S., M. Daniel, H. Tilly, P. Herait, and L. Degos. 1983. Does treatment with ara-C in low dosage cause differentiation of leukemic cells? Blood. 62:85-86.

27. Baccarani, M., A. Zaccaria, G. Bandini, G. Cavazzini, R. Fani, and S. Tura. 1983. Low dose arabinosyl cytosine for treatment of myelodysplastic syndromes and subacute myeloid leukemia. Leukemia Res. 7:539-545.

28. Kovach, J. S., R. A. Marks, E. S. Russell, and H. Epler. 1967. Erythroid cell development in fetal mice: ultrastructural characteristics and hemoglobin synthesis. J. Mol. Biol. 25:131-142. 